ORIGINAL ARTICLE

\title{
The sleep problems diagnosed among children with autistic spectrum disorder (ASD).
}

\author{
Sehar Ashraf ${ }^{1}$, Taimoor Hassan $^{2}$, Sana Saeed $^{3}$, Sidra Siddique $^{4}$, Amina Tahir $^{5}$, Zahid Hussain $^{6}$
}

Article Citation: Ashraf S, Hassan T, Saeed S, Siddique S, Tahir A, Hussain Z. The sleep problems diagnosed among children with autistic spectrum disorder (ASD). Professional Med J 2022; 29(3):310-315. https://doi.org/10.29309/TPMJ/2022.29.03.6580

\begin{abstract}
Objective: To find the sleep problems in children who are diagnosed with Autism Spectrum Disorder between the age ranges from 3 to 12 years. Study Design: Cross-sectional Observational study. Setting: Department of the Developmental Pediatrics Children Hospital Lahore and Department of Occupational Therapy, Rising Sun, Lahore. Period: February 2017 to November 2017. Material \& Methods: This study included 300 children who were diagnosed with ASD having sleep problems between ages 3-12 years. All other children were excluded. Data was collected by using Albany sleep problem scale. The sample size was determined by utilizing WHO Software for test size assurance in wellbeing considers. Results: Results demonstrated that majority of the kids presented with different sleep disorders such as (83\%) of the children took a lot of time to sleep. Moreover, (43.2\%) of the children depicted continuous awakening during night time. (63.4\%) of the kids faced Respiratory problems. (53\%) children showed restlessness during sleep. Furthermore, (83.3\%) of the children remained consciousness during sleep. Conclusion: Study concluded that most habitually sleep issues in ASD kids are nodding off, fretful rest, not falling stay in own bed, take an hour to sleep, kicking legs and successive enlightenments. Less commonly sleep problems were sleep strolling, sleep talking, and resistance to go in bed, excessive sleep-in day screams uproariously.
\end{abstract}

Key words: $\quad$ Autism, Autistic Child, Autistic Disorder, Autism Spectrum Disorder, Childhood, Sleep Disorders.

\section{INTRODUCTION}

Autism Spectrum Disorder (ASD) is a developmental disability that is described by communication and social impairments in relation to repetitive and restricted behaviors. ${ }^{1}$ Hypothetically, ASD is considered as a continuum of mental and psychological conditions that necessitates moderate to substantial support to overcome with deficits and lags in social interaction, repetitive \& restricted behaviors. ${ }^{2}$ Sleep difficulties are often considered as comorbidities of Autism Spectrum Disorder. ${ }^{3}$ Lack of sleep and decreased sleep quality also exerts a deteriorating impact on learning abilities, emotional processing and social interactions. ${ }^{4}$ Meta-scale studies $(n>1000)$ who are published in the previous five years reported sleep problems in ranges from 30 to $72 \%$ of children and adolescents who are diagnosed with ASD. ${ }^{5}$
Children with ASD are more likely to show sleep related problems $(48 \%)$ as compared to their other siblings, $16 \%$, when the family factors are well controlled like noisy environment, stress, child-rearing practices (no supervision from their parents). ${ }^{6}$

Sleep disturbances have also been reported among adults with prominent signs of ASD youngsters are that they does not respond to name by three hundred and sixty five days of age, avoids eye-to-eye contact, likely to play their own, delayed speech and language competencies, reverses pronouns (e.g., says "you" in place of "I"), gives unrelated answers to questions, Does not point or reply to pointing, lays with toys the equal manner on every occasion, traces up toys or different objects, Play likes components of items (e.g., wheels), gets dissatisfied by using

1. BSc (Hons), MS (Scholar), Occupational Therapist, The University of Lahore.

2. BSc (Hons), Masters of Pharmacy (Scholar), School of Pharmacy \& School of Medicine, Changzhou University, Jiangsu, China. Department of Health Professional Technologies, The University of Lahore, Pakistan.

3. BSc (Hons), School of Allied Health Sciences, Children Hospital Lahore. Lecturer, Department of Health Professional Technologies, The University of Lahore.

4. BSc (Hons), (Gold Medalist), School of Allied Health Sciences, Children Hospital Lahore.

5. B.Sc, (Hons), Occupational Therapist, The University of Lahore.

6. MBBS, FRCS, FCPS, Director, Sharif Hospital Lahore.

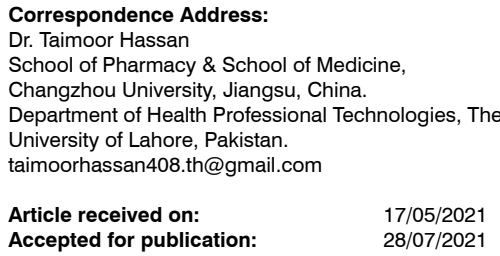


minor modifications, has obsessive pursuits, has to observe positive workouts, Flaps hands, or spins self in circles, rocks body, unusual reactions to the manner things sound. Sleep is not a uni-process but it includes multiple cycles that variates from rapid eye movement (REM) to Non-rapid eye movement (NREM). ${ }^{7}$

Sleep can further by subcategorized into Nonrapid eye movement 1 , Non-rapid eye movement 2, Non-rapid eye movement 3 degrees that explicit some characteristics like sufficient electroencephalographic hobby with low muscle tone, growing lazy, and gradual or no eye actions. ${ }^{8}$ ASD is associated with a higher prevalence of behavioral insomnia syndrome, Delayed sleep phase, obstructive sleep apnea. Parasomnias like; disoriented waking, bedwetting, night terrors, bruxism, rhythmic movements while falling asleep, sleep walking, and acting out dreams. $^{9}$ Based on several questionnaires, a cross-sectional study across lifespan reports more, sleep anxiety, bedtime resistance, and night waking in children with ASD, parasomnias, where-as adolescents who are also victim of ASD features more daytime sleepiness, delayed sleep onset, shorter sleep duration. ${ }^{10}$ Sleep disturbances in the victims of ASD can be referred to environmental, social, biological, psychological. Co-morbid medical conditions may also aggravate sleep disturbances in people with Autism Spectrum Disorder such as, epilepsy, attention-deficit hyperactivity disorder, asthma pain and GI problems. Since, ASD patients are very sensitive, they more often fall asleep in their parent's arms. ${ }^{11}$ Similarly, in fact little changes affects their behavior much.

A study conducted on ASD's victims stated that sensitivity abnormalities also trigger sleep problems. $^{12}$ Conversely, the hypersensitivity in ASD's victims imparts anxiety, un-easiness, mood-swings on bed at home, for instance when they brush their teeth it assists in sleeping difficulty. ${ }^{13}$ One of the studies confirms that children with auditory dysfunctions, have more troubled sleeping. ${ }^{14}$ Sleep difficulties are somewhat associated with poor developmental functioning in toddlers or infants. In children and adolescents, sleep disturbances, like; less sleep duration, predicts ASD symptom severity. Poor ASD sleepers have high problems in social interactions with other people. ${ }^{15}$ Symptoms of insomnia described as difficulty beginning or preserving sleep, are the essential sleep worries mentioned through dad and mom of youngsters with ASD. ASD are more likely to show off insomnia with extended sleep latency (time to doze off), bedtime resistance, reduced sleep performance (decreased time asleep on the subject of time in bed), decreased sleep period and continuity, and increased awakenings. normal, sleep-onset insomnia (issue falling asleep) is extra common place, in comparison with sleep preservation insomnia (difficulty staying asleep) although children with ASD frequently revel in factors of both). ${ }^{16}$ Psychiatric co morbidities, including attention-deficit/hyperactivity disease (ADHD), and obsessive/repetitive conduct, anxiety/ depression can additionally make contributions to insomnia and may also additionally be exacerbated via insomnia. ${ }^{17,18,19}$ The rationale of this study is that, there are very less studies in Pakistan which address this disorder among children.

\section{MATERIAL \& METHODS}

It was an observational and cross-sectional study that included children who were diagnosed with Autism Spectrum Disorder. Data was collected from the Department of Developmental Pediatrics Children Hospital Lahore \& Department of Occupational Therapy, Rising Sun, Lahore. The study duration was nine months from February 2017 to November 2017. 300 Children were added in our study. The sample size was determined by utilizing WHO Software for test size assurance in wellbeing considers. (Wanga and Limeshow, 2001). Convenient sampling technique were applied. The children with diagnosis of ASD having sleep problems between age range 3-12 years were included in this study. While, and all other children who were not fulfilling the abovementioned criteria were excluded. Data was collected by using Albany sleep problem scale. This research was analyzed by using software SPSS version 24. Ethical committee approval was taken prior to research from the Institutional 
Review Board (IRB) of Children Hospital Lahore (2325/SAHS).

\section{RESULTS}

Table-I shows that $50 \%$ of autistic children have not oppositional behavior whereas $23 \%$ showed this behavior less than once per week, $4 \%$ showed one to three times in a week, $2 \%$ three to six times per week and $6.7 \%$ showed nightly. It is observed that wake mid night behavior is observed $23.3 \%$ less than once per week, $13.3 \%$ one to three times per week, $3.3 \%$ children showed three to six times per week and $10 \%$ showed this behavior nightly. $16.7 \%$ children showed screaming at night less than once per week, $6.7 \%$ one to three times per week, $3.3 \%$ showed this behavior three to six times per week.

Table-Il shows that play in bed behavior of autistic children have $23.3 \%$ less than once per week, $13.3 \%$ one to two times per week, $10 \%$ showed three to six times per week and $13.3 \%$ showed nightly. Vigorous activity behavior showed by autistic child $23.3 \%$ less than once per week, $16.7 \%$ one to two times per week, $6.7 \%$ three to six times per week, $20 \%$ showed nightly.

Resistance to go in bed behavior of autistic child $16.7 \%$ less than once per week, $10 \%$ one to two times per week and $3.3 \%$ showed nightly. The children that take one an hour to sleep less than once per week is $26.7 \%$, one to two times per

\begin{tabular}{|l|l|l|l|l|l|l|}
\hline \multicolumn{1}{|c|}{ Nightmare } & \multicolumn{1}{|c|}{ Total } & Never & $\begin{array}{c}\text { Less Than } \\
\text { Once Per } \\
\text { Week }\end{array}$ & $\begin{array}{c}\text { One to Three } \\
\text { Two Per Week }\end{array}$ & $\begin{array}{c}\text { Three to Six } \\
\text { Time Per } \\
\text { Week }\end{array}$ & \multicolumn{1}{|c|}{ Nightly } \\
\hline oppositional & $300(100 \%)$ & $150(50 \%)$ & $70(23.3 \%)$ & $40(13.3 \%)$ & $20(6.7 \%)$ & $20(6.7 \%)$ \\
\hline Wake mid night & $300(100 \%)$ & $150(50 \%)$ & $70(23.3 \%)$ & $40(13.3 \%)$ & $10(3.3 \%)$ & $30(10 \%)$ \\
\hline Screams loudly & $300(100 \%)$ & $220(73.3 \%)$ & $50(16.7 \%)$ & $20(6.7 \%)$ & $10(3.3 \%)$ & 00 \\
\hline
\end{tabular}

\begin{tabular}{|l|l|l|l|l|l|l|}
\hline \multicolumn{1}{|c|}{ Insomnia } & Total & Never & $\begin{array}{c}\text { Less Than } \\
\text { Once Per } \\
\text { Week }\end{array}$ & $\begin{array}{c}\text { One To Two } \\
\text { Time Per } \\
\text { Week }\end{array}$ & $\begin{array}{c}\text { Three To Six } \\
\text { Time Per } \\
\text { Week }\end{array}$ \\
\hline Play in bed & $300(100 \%)$ & $120(40 \%)$ & $70(23.3 \%)$ & $40(13.3 \%)$ & $30(10 \%)$ & $40(13.3 \%)$ \\
\hline Vigorous activity & $300(100 \%)$ & $100(33.3 \%)$ & $70(23.3 \%)$ & $50(16.7 \%)$ & $20(6.7 \%)$ & $60(20 \%)$ \\
\hline Resist to bed & $300(100 \%)$ & $210(70 \%)$ & $50(16.7 \%)$ & $30(10 \%)$ & 00 & $10(3.3 \%)$ \\
\hline Take an hour to sleep & $300(100 \%)$ & $50(16.7 \%)$ & $80(26.7 \%)$ & $60(20.0 \%)$ & $30(10.0 \%)$ & $80(26.7 \%)$ \\
\hline Awake at night & $300(100 \%)$ & $170(56.7 \%)$ & $100(33.3 \%)$ & $10(3.3 \%)$ & $10(3.3 \%)$ & $10(3.3 \%)$ \\
\hline Difficult to sleep/awake & $300(100 \%)$ & $150(50 \%)$ & $60(20.0 \%)$ & $50(16.7 \%)$ & 00 & $40(13.3 \%)$ \\
\hline & & Table-II. Frequency of insomnia. & & \\
\hline
\end{tabular}

week is $20 \%$, three to six times per week is $10 \%$ and $26.7 \%$ showed this behavior nightly. $33.3 \%$ of children awake at night less than once per week, 3.3\% one to two times per week, three to six times per week as well as nightly Difficult to sleep behavior of children showed $20 \%$ less than once per week, $16.7 \%$ one to two times per week, $13.3 \%$ showed this behavior nightly.

Table-III shows that Snoring behavior by autistic children showed $30 \%$ less than once per week, $3.3 \%$ showed one to two times per week. 3.3\% showed three to six times per week, 3.3\% showed this behavior nightly. $33.3 \%$ autistic children facing breathing difficulty $33.3 \%$ less than once per week, $16.7 \%$ showed one to two times per week, $3.3 \%$ showed this behavior nightly.

Table-IV shows that Teeth grinding behavior in autistic child is observed $30 \%$ less than once per week, $10 \%$ one to two times per week, $6.7 \%$ three to six times per week and $13.3 \%$ showed this behavior nightly. Banging behavior frequency is $23 \%$ less than once per week, $6.7 \%$ one to two times per week and $33.3 \%$ nightly. Kicking leg behavior is observed $36.7 \%$ less than once per week, $3.3 \%$ one to two times per week and $13.3 \%$ showed this behavior nightly. Body movement is observed by an autistic children are $26.7 \%$ less than once per week, $10 \%$ showed one to two times per week, $6.7 \%$ showed three to six times per week and $10 \%$ showed this behavior nightly. 


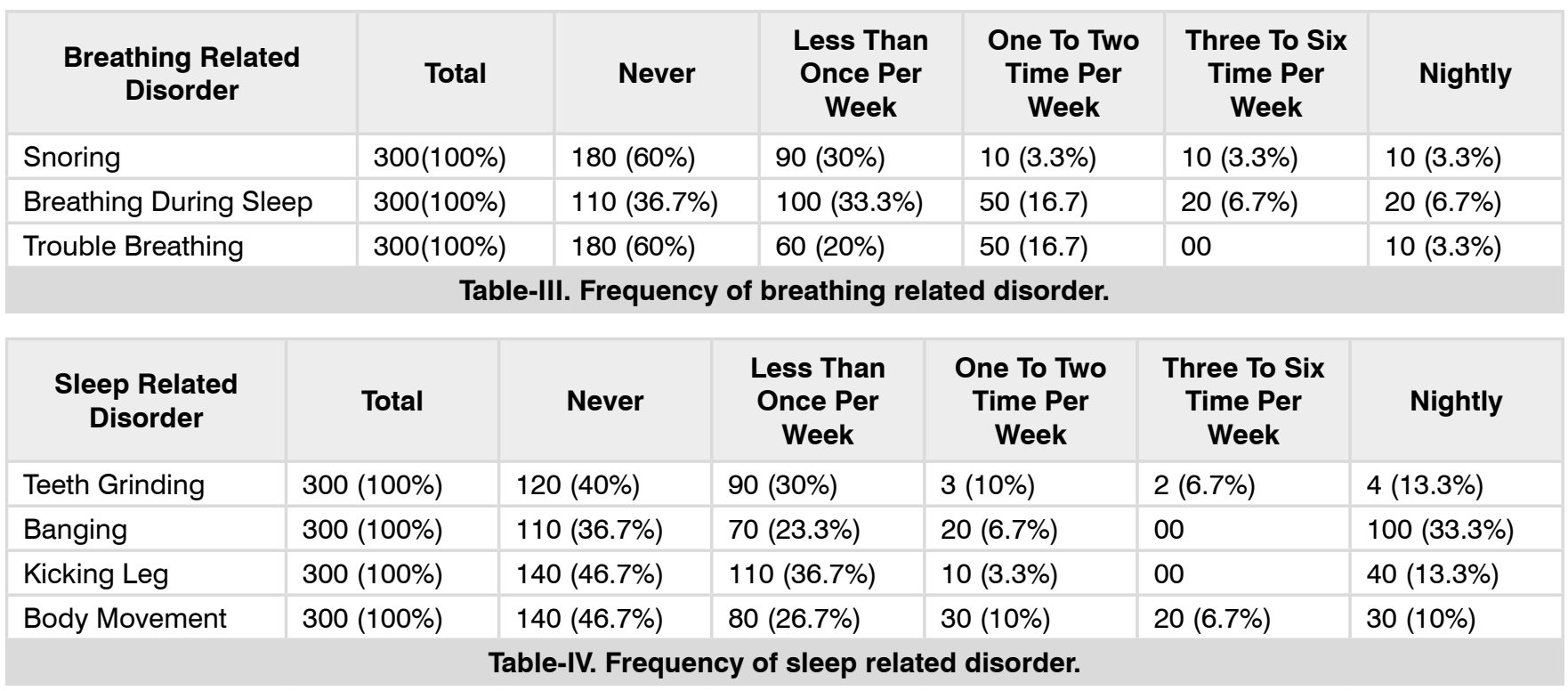

\section{DISCUSSION}

Many studies on insomnia or parasomnias in Autism have reported widely inconsistent results. Some of the studies reported that incidence of parasomnia slow. Consequently, four studies exhibit that Autistic Children often prone to parasomnias. ${ }^{20}$

A study demonstrated that ASD victimized adolescents and children suffer insomnia with higher rate $(40 \%$ to $80 \%)$ then normal children. ${ }^{21}$ A research works on sleep disorder in ASD. This study examined sleep related problems, and their correlations autistic children. Participants included 167 ASD children, among them 108 with autistic disorder, 27 with Asperger's syndrome, and 32 with other/more diagnoses of ASD. The Mean age was 8.8 years, $86 \%$ were boys. The results showed that average night sleep duration was 8.9 hours $(S D=1.8), 16 \%$ of children shared bed with their parents. About $86 \%$ of children had at least one sleep problem almost every day, including 56\% with insomnia, 53\% with parasomnias, $54 \%$ with bedtime resistance, $25 \%$ with sleep disordered breathing, $45 \%$ with morning rise problems, and $31 \%$ with daytime sleepiness. ${ }^{22}$

A group of scientists conducted a study on pediatric insomnia, they concluded that it is the commonest sleep disorder in pediatrics by stating that approximately $30 \%$ of the patients undergoes from this disorder, it is characterized by multiple awakening sessions, sleep-agitations, poor hygiene, Furthermore, in few cases, behavioral insomnia can activates co-morbidities like; Obstructive sleep apneas, epilepsy, restless legs syndrome, limb movement in state of sleep and daytime sleeping, bruxism. ${ }^{23}$ Results of the present study correlate with the study of Miano and giannotti. Children who shows resistance to go to bed (30\%), children take an hour to sleep (83.3\%), awake at night (43.2\%), napping (23.3\%) breathing related disorders (63.4\%), wake mid night ( $43.2 \%)$, kicking leg (53.3\%), play in bed $(59.9 \%)$,difficulty to sleep awake (50\%), early to sleep awake (83.3\%), excessive sleep in day $(36.6 \%)$, snoring $(39.9 \%)$, trouble breath $(40 \%)$, oppositional (50\%), screams loudly (26.7\%), sleep walking $(15.7 \%)$, sleep talking $(16.7 \%)$, teeth grinding $(60 \%)$, banging $(63.3 \%)$, body movements $(53.4 \%) .{ }^{24}$

A cross-sectional study was conducted to evaluate the condition about worsening of anxiety of sleep and improvement in the bedtime activities. Unluckily, the measurements objective of sleep in Autism Spectrum Disorder infants and toddlers are not mentioned or skipped as previous studies that involves questionnaires filled by their caregivers about parasomnias, short sleep duration, resistance in bedtime, sleepiness in daytime, walking at night, crying while wakingup before an age of two years. ${ }^{25}$ 


\section{CONCLUSION}

Study concluded that most habitually sleep issues in ASD kids are nodding off, fretful rest, not falling stay in own bed, take an hour to sleep, kicking legs and successive enlightenments. Less commonly sleep problems were sleep strolling, sleep talking, and resistance to go in bed, excessive sleep-in day screams uproariously.

Copyright(C 28 July, 2021.

\section{REFERENCES}

1. Heinsfeld AS, Franco AR, Craddock RC, Buchweitz $A$, Meneguzzi $F$. Identification of autism spectrum disorder using deep learning and the ABIDE dataset. Neurolmage: Clinical. 2018 Jan 1; 17:16-23.

2. Campisi L, Imran N, Nazeer A, Skokauskas N, Azeem MW. Autism spectrum disorder. British Medical Bulletin. 2018 Sep 1; 127(1).

3. Loomes R, Hull L, Mandy WP. What is the maleto-female ratio in autism spectrum disorder? A systematic review and meta-analysis. Journal of the American Academy of Child \& Adolescent Psychiatry. 2017 Jun 1; 56(6):466-74.

4. Xu G, Strathearn L, Liu B, Bao W. Prevalence of autism spectrum disorder among US children and adolescents, 2014-2016. Jama. 2018 Jan 2; 319(1):812.

5. Sharma SR, Gonda X, Tarazi FI. Autism spectrum disorder: classification, diagnosis and therapy. Pharmacology \& therapeutics. 2018 Oct 1; 190:91-104.

6. Dean M, Harwood R, Kasari C. The art of camouflage: Gender differences in the social behaviors of girls and boys with autism spectrum disorder. Autism. 2017 Aug; 21(6):678-89.

7. Kogan MD, Vladutiu CJ, Schieve LA, Ghandour RM, Blumberg SJ, Zablotsky B, Perrin JM, Shattuck P, Kuhlthau KA, Harwood RL, Lu MC. The prevalence of parent-reported autism spectrum disorder among US children. Pediatrics. 2018 Dec 1; 142(6).

8. Masi A, DeMayo MM, Glozier N, Guastella AJ. An overview of autism spectrum disorder, heterogeneity and treatment options. Neuroscience bulletin. 2017 Apr 1; 33(2):183-93.

9. Hollocks MJ, Lerh JW, Magiati I, Meiser-Stedman R, Brugha TS. Anxiety and depression in adults with autism spectrum disorder: A systematic review and meta-analysis. Psychological medicine. 2019 Mar; 49(4):559-72.
10. Sgritta $M$, Dooling SW, Buffington SA, Momin EN, Francis MB, Britton RA, Costa-Mattioli M. Mechanisms underlying microbial-mediated changes in social behavior in mouse models of autism spectrum disorder. Neuron. 2019 Jan 16; 101 (2):246-59.

11. Pierce K, Gazestani VH, Bacon E, Barnes CC, Cha D, Nalabolu S, Lopez L, Moore A, Pence-Stophaeros S, Courchesne E. Evaluation of the diagnostic stability of the early autism spectrum disorder phenotype in the general population starting at 12 months. JAMA pediatrics. 2019 Jun 1; 173(6):578-87.

12. Guang S, Pang N, Deng X, Yang L, He F, Wu L, Chen C, Yin F, Peng J. Synaptopathology involved in autism spectrum disorder. Frontiers in cellular neuroscience. 2018 Dec 21; 12:470.

13. Agrawal S, Rao SC, Bulsara MK, Patole SK. Prevalence of autism spectrum disorder in preterm infants: A meta-analysis. Pediatrics. 2018 Sep 1; 142(3).

14. Spain D, Sin J, Linder KB, McMahon J, Happé F. Social anxiety in autism spectrum disorder: A systematic review. Research in Autism Spectrum Disorders. 2018 Aug 1; 52:51-68.

15. George R, Stokes MA. Gender identity and sexual orientation in autism spectrum disorder. Autism. 2018 Nov; 22(8):970-82.

16. Milner V, Mclntosh H, Colvert E, Happé F. A qualitative exploration of the female experience of autism spectrum disorder (ASD). Journal of autism and developmental disorders. 2019 Jun; 49(6):2389-402.

17. Satterstrom FK, Walters RK, Singh T, Wigdor EM, Lescai F, Demontis D, Kosmicki JA, Grove J, Stevens C, Bybjerg-Grauholm J, Bækvad-Hansen M. Autism spectrum disorder and attention deficit hyperactivity disorder have a similar burden of rare proteintruncating variants. Nature neuroscience. 2019 Dec; 22(12):1961-5.

18. Howlin P, Magiati I. Autism spectrum disorder: Outcomes in adulthood. Current Opinion in Psychiatry. 2017 Mar 1; 30(2):69-76.

19. Livingston LA, Colvert E, Social Relationships Study Team, Bolton P, Happé F. Good social skills despite poor theory of mind: Exploring compensation in autism spectrum disorder. Journal of Child Psychology and Psychiatry. 2019 Jan; 60(1):102-10.

20. Varghese M, Keshav N, Jacot-Descombes S, Warda T, Wicinski B, Dickstein DL, Harony-Nicolas H, De Rubeis S, Drapeau E, Buxbaum JD, Hof PR. Autism spectrum disorder: Neuropathology and animal models. Acta neuropathologica. 2017 Oct; 134(4):537-66. 
21. Mesa-Gresa P, Gil-Gómez H, Lozano-Quilis JA, GilGómez JA. Effectiveness of virtual reality for children and adolescents with autism spectrum disorder: An evidence-based systematic review. Sensors. 2018 Aug; 18(8):2486.

22. Hudson CC, Hall L, Harkness KL. Prevalence of depressive disorders in individuals with autism spectrum disorder: A meta-analysis. Journal of Abnormal Child Psychology. 2019 Jan; 47(1):165-75.

23. Scott M, Milbourn B, Falkmer M, Black M, B $\square$ lte S, Halladay A, Lerner M, Taylor JL, Girdler S. Factors impacting employment for people with autism spectrum disorder: A scoping review. Autism. 2019 May; 23(4):869-901.
24. Anderson $\mathrm{AH}$, Carter M, Stephenson J. Perspectives of university students with autism spectrum disorder. Journal of autism and developmental disorders. 2018 Mar; 48(3):651-65.

25. Colizzi M, Sironi E, Antonini F, Ciceri ML, Bovo C, Zoccante L. Psychosocial and behavioral impact of COVID-19 in autism spectrum disorder: An online parent survey. Brain Sciences. 2020 Jun; 10(6):341.

\begin{tabular}{|c|l|l|l|}
\hline \multicolumn{2}{|c|}{ AUTHORSHIP AND CONTRIBUTION DECLARATION } \\
\hline No. & \multicolumn{1}{|c|}{ Author(s) Full Name } & \multicolumn{1}{|c|}{ Contribution to the paper } & Author(s) Signature \\
\hline 1 & Sehar Ashraf & Write-up. & \\
\hline 2 & Taimoor Hassan & $\begin{array}{l}\text { Write-up. Discussion and } \\
\text { Critical review. } \\
\text { Data collection \& Discussion. }\end{array}$ \\
\hline 3 & Sana Saeed & Sata collection. \\
\hline 5 & Amina Tahir & Statsitical analysis. & \\
\hline 6 & Zahid Hussain & Statistical analysis \& Final \\
\end{tabular}

